\title{
A topographical model for precipitation pattern in the Tibetan Plateau
}

QI Wen-wen",2 (Dhttp://orcid.org/oooo-ooo2-8439-4339; e-mail: qiww@lreis.ac.cn

ZHANG Bai-ping1,3 iD http://orcid.org/oooo-0oo3-4298-9526; e-mail: zhangbp@lreis.ac.cn

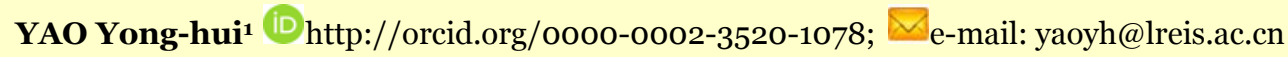

ZHAO Fang1,2 (iD http://orcid.org/oooo-0oo1-9225-104X; e-mail: zhaofang@lreis.ac.cn

ZHANG Shuo',2 iD http://orcid.org/oooo-ooo1-7842-5875; e-mail: zhangs@lreis.ac.cn

HE Wen-hui',2 (D http://orcid.org/oooo-0oo2-9155-3393; e-mail: hewh@lreis.ac.cn

\begin{abstract}
1 State Key Laboratory of Resource and Environment Information System, Institute of Geographic Sciences and Natural Resources Research, Chinese Academy of Sciences, Beijing 100101, China

2 University of Chinese Academy of Sciences, Beijing 10oo49, China

3 Jiangsu Center for Collaborative Innovation in Geographical Information Resource Development and Application, Nanjing 210023, China
\end{abstract}

Citation: Qi WW, Zhang BP, Yao YH, et al. (2016) A topographical model for precipitation pattern in the Tibetan Plateau. Journal of Mountain Science 13(5). DOI: 10.1007/s11629-015-3522-x

(C) Science Press and Institute of Mountain Hazards and Environment, CAS and Springer-Verlag Berlin Heidelberg 2016

\begin{abstract}
As the highest and most extensive plateau on earth, the Tibetan Plateau has strong thermodynamic effect, which not only affects regional climate around the plateau but also temperature and precipitation patterns of itself. However, due to scattered meteorological stations, its spatial precipitation pattern and, especially, the mechanism behind are poorly understood. The availability of spatially consistent satellite-derived precipitation data makes it possible to get accurate precipitation pattern in the plateau, which could help quantitatively explore the effect and mechanism of mass elevation effect on precipitation pattern. This paper made full use of TMPA $3 \mathrm{~B} 43 \mathrm{~V}_{7}$ monthly precipitation data to track the trajectory of precipitation and identified four routes (east, southeast, south, west directions) along which moisture-laden air masses move into the plateau. We made the assumption that precipitation pattern is the result interplay of these four moistureladen air masses transportation routes against the distances from moisture sources and the topographic
\end{abstract}

Received: 25 March 2015

Received: 19 January 2016

Accepted: 1 April 2016 barriers along the routes. To do so, we developed a multivariate linear regression model with the spatial distribution of annual mean precipitation as the dependent variable and the topographical barriers to these four moisture sources as independent variables. The result shows that our model could explain about $70 \%$ of spatial variation of mean annual precipitation pattern in the plateau; the regression analysis also shows that the southeast moisture source (the Bay of Bengal) contributes the most (32.56\%) to the rainfall pattern of the plateau; the east and the south sources have nearly the same contribution, 23.59\% and 23.48\%, respectively; while the west source contributes the least, only $20.37 \%$. The findings of this study can greatly improve our understanding of mass elevation effect on spatial precipitation pattern.

Keywords: Tibetan Plateau; Precipitation pattern; Topography; Moisture sources

\section{Introduction}

Topography influences the spatial distribution 
of precipitation in mountainous regions. Exploring the spatial pattern of precipitation in relation to topography is significant for understanding the mechanism of precipitation in mountains and high plateaus where observed meteorological data are often quite limited (Basist et al. 1994). This is especially the case for the massive Tibetan Plateau (Fielding et al. 1994), about 2.5 million $\mathrm{km}^{2}$ in area and $4500 \mathrm{~m}$ in elevation standing as the most extensive and highest plateau in the world. It is bordered to the south and west by Chinese national boundary (roughly the Himalayas and the Karakoram), to the north by the Kunlun Range, to the northeast by the Qilian Range, and to the east and southeast by the Sichuan Basin and Hengduan Mountains. Due to its immensity, the plateau has strong thermal and dynamical effects, and significantly influences the climate and ecosystems of the plateau and its adjacent regions (Ye and $\mathrm{Wu}$ 1998; Li and Fang 1998). From southeast to northwest, montane forest, alpine meadow, alpine steppe, and alpine desert appear in succession, reflecting a spatial trend of precipitation decreasing northwestwards.

Precipitation pattern in the Tibetan Plateau has been explored by using station observed data. It was shown that the mean annual rainfall decreases from about $2000 \mathrm{~mm}$ in the southeast to about $50 \mathrm{~mm}$ in the northwest (Liao 1990; Lin et al. 2000; Owen et al. 2005). Some conceptual models have been developed to explain the spatial pattern of precipitation in the plateau. For example, Liu and Yin (2002) argued that the Tibetan Plateau is dominated by two climatic systems-the mid-latitude westerly and the South Asia monsoon; most of the southern and eastern regions of the plateau are remarkably affected by summer monsoon, which carries moisture-laden air masses from the Indian Ocean northwards (Ye and $\mathrm{Wu}$ 1998). Gao et al. (1985) and Yang et al. (1987) noticed a close relationship between plentiful precipitation and moist air masses transportation along the lower Yarlung Zangbo River. Zhang (2000) reported that the mid-latitude westerly, which carries moisture from the Arabian Sea, brings winter precipitation onto the western Himalayas and the Karakoram Mountains. The northern part of the plateau is far away from both circulation systems (Liu and Yin 2002), and the annual precipitation is quite limited, only about 50 $\mathrm{mm}$ or even less. The spatial and temporal distribution pattern of precipitation over the plateau fits quite well with the transportation routes of moisture-laden air masses from the Bay of Bengal and the Arabian Sea (Lin and Zheng 1991).

The studies stated above used observed climatic data and are useful for understanding the general distribution of precipitation in macroscale. However, due to the scarcity of meteorological stations and limited climatic data in the plateau, especially in its western half, very little information on the precipitation patterns of the plateau is quantitatively known. In recent years, satellite data become available for estimating precipitation over large areas with spatial and temporal consistency (Gao and Liu 2013). It has been demonstrated that satellite derived data have great potential in accurate mapping of precipitation pattern in the Tibetan Plateau (Anders et al. 2006; Hao et al. 2011; Jia et al. 2011; $\mathrm{Ji}$ and Chen 2012; Zeng and Li 2012; Qi et al. 2013). We consider that the high-resolution precipitation pattern so worked out should be well elucidated. Atmospheric circulation is of course the main factor and has been well studied. Here, we suppose that mountain topography also plays a role in forming macroscopic precipitation pattern in massive mountains or plateaus; however, study of topographic influence on precipitation pattern is still lacking in the Tibetan Plateau. This paper tries to quantitatively study the effect of macro-scale topography on spatial precipitation pattern in the plateau.

\section{Materials and Methods}

\subsection{Data and pre-processing}

This paper used three sets of data, namely, precipitation, SRTM DEM (raster data), and reanalysis for water vapor content (point data). Precipitation data are taken to map precipitation footprints and as dependent variable to develop precipitation model; SRTM DEM is used to produce independent variables in precipitation model; and reanalysis data are used to determine moisture content in water-vapor source areas. 


\subsubsection{Spatial Pattern of Mean Annual Precipitation in the Tibetan Plateau}

The Tropical Rainfall Measuring Mission (TRMM) is a joint U.S.-Japan satellite mission to monitor tropical and subtropical precipitation (Kummerow et al. 1998). Algorithm 3B43 is executed once per calendar month to produce the single, best-estimate precipitation rate and RMS precipitation-error estimate field (3B43) by combining the 3-hourly merged high-quality/IR estimates with the monthly accumulated Global Precipitation Climatology Centre (GPCC) rain gauge analysis (Huffman et al. 2007). This TRMM Multi-satellite Precipitation Analysis (TMPA) 3 B43 dataset has a spatial resolution of $0.25^{\circ} \times 0.25^{\circ}$ and can be downloaded from http://trmm.gsfc.nasa. gov/data_dir/ProductStatus.html.

We have ever compared the TMPA 3 B43 data with ground based data (Qi et al. 2013) and found that the TMPA 3 B43-derived data overestimate the precipitation in the northwest of the Tibetan Plateau during the non-monsoon period, while underestimate precipitation in the southeast part during the monsoon season. According to this spatial error distribution of the TMPA 3 B43 data, we improved the accuracy of the TMPA $3 \mathrm{~B}_{43}-$ derived data based on meteorological data of 114 ground stations in the plateau (Figure 1).

This study will first use the monthly TMPA 3B43 dataset (Version 7) to track the trajectories of precipitation in the plateau. Then, the improved mean annual precipitation data from our previous work (Qi et al. 2013) will be used as the dependent variable to develop a topographical model for precipitation pattern in the plateau.

\subsubsection{NCEP/NCAR Reanalysis Data}

The National Centers for Environmental Prediction/National Center for Atmospheric Research (NCEP/NCAR) reanalysis data during the period 1981-2010 are used to estimate the watervapor moving trajectories over and around the Tibetan Plateau, with a spatial resolution of $2.5^{\circ} \times 2.5^{\circ}$ (Kalnay et al. 1996). The quality of the reanalysis data in estimating water vapor moving routes has been evaluated over the Tibetan Plateau (Feng and Zhou 2012; You et al. 2012). They are available for free download http://www.esrl.noaa.

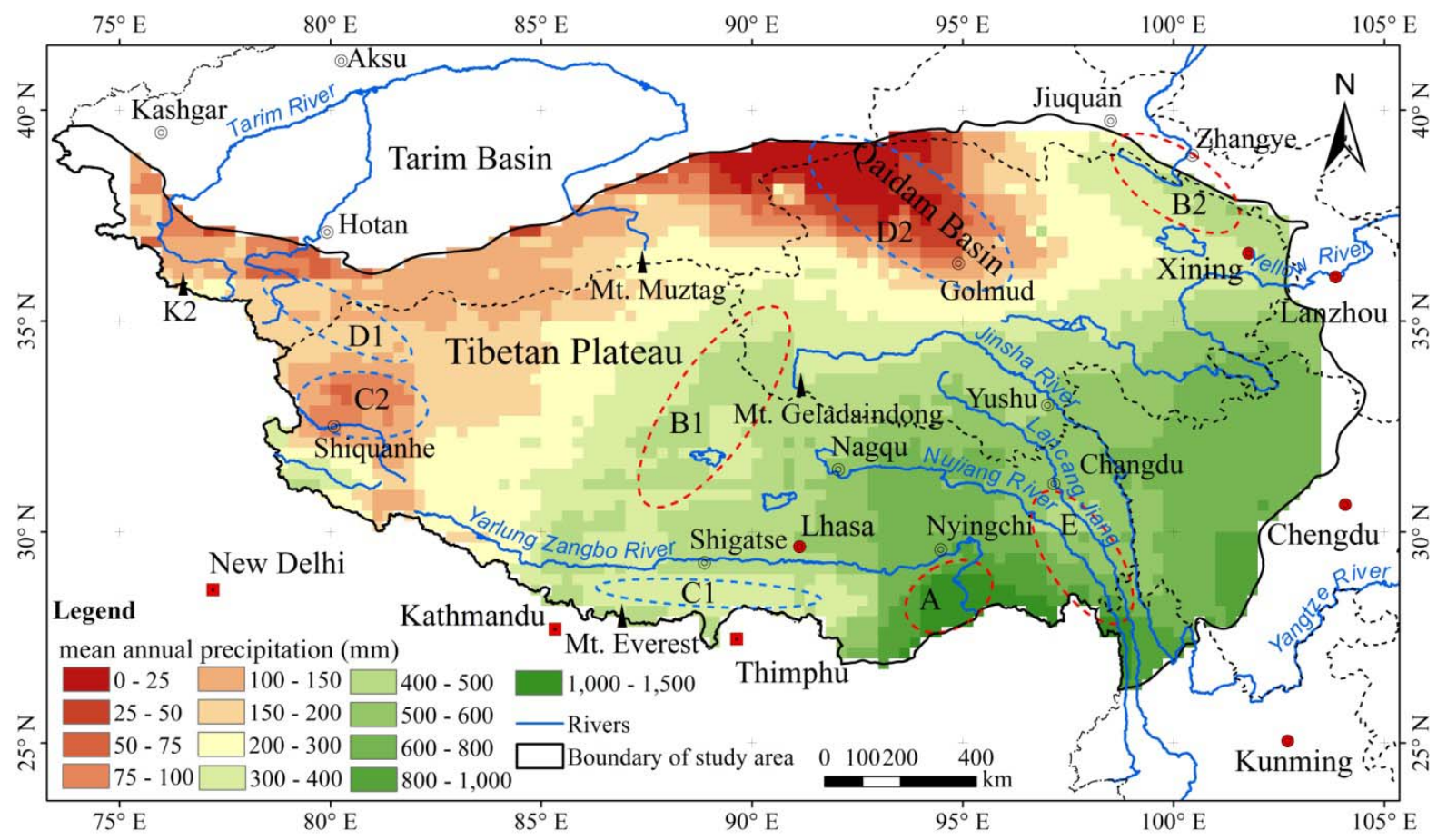

Figure 1 Spatial pattern of mean annual precipitation $(\mathrm{mm})$ in the Tibetan Plateau based on improved TMPA $3 \mathrm{~B} 43$ estimates by meteorological data of 114 ground stations (Qi et al. 2013). A: humid region (the lower Yarlung Zangbo); B: relatively humid regions (B1- the Qiangtang Plateau; B2-the southern flank of the Qilian Mountains); C: arid regions (C1- the rain shadow in the northern flank of the Himalayas, C2-the Ngari-Karakoram Mountains); D: extremely arid regions (D1: the northern cold-arid core, D2-the Qaidam Basin); E: relatively arid region (the central part of the Hengduan Mountains). 
gov/psd/data/gridded/data.ncep.reanalysis.html.

The vertically integrated water vapor flux can be expressed as (Peixoto and Oort 1983):

$$
Q=\frac{1}{g} \int_{P t}^{P_{s}} q V \mathrm{~d} p
$$

where $Q$ is the atmospheric water vapor flux for a vertical column of the atmosphere with unit base $\left(\mathrm{kg} \cdot \mathrm{m}^{-1} \cdot \mathrm{s}^{-1}\right), g$ acceleration due to gravity $\left(\mathrm{m} \cdot \mathrm{s}^{-2}\right), q$ specific humidity $\left(\mathrm{g} \cdot \mathrm{kg}^{-1}\right), P_{s}$ pressure at surface level; $V$ is wind speed vector $\left(\mathrm{m} \cdot \mathrm{s}^{-1}\right)$, and $V=u+v$, where $u$ is zonal wind component (positive if eastward, $\mathrm{m} \cdot \mathrm{s}^{-1}$ ), and $v$ meridional wind component (positive if northward, $\mathrm{m} \cdot \mathrm{s}^{-1}$ ); $P_{t}$ is the pressure at the top level of the vertical isobaric levels including surfaces/1000, 925, 850, 700, 600, 500, 400 and $300 \mathrm{hPa}$.

\subsubsection{SRTM DEM}

The SRTM DEM data can be freely downloaded from the website (http://srtm.csi.cgiar.org/). Its resolution is three-arc-second (approx. $90 \mathrm{~m}$ ). The data are projected in a Geographic (Lat/Long) projection, with the WGS84 horizontal datum and the EGM96 vertical datum. The vertical error of the data is reported to be less than $16 \mathrm{~m}$ and the horizontal error less than $20 \mathrm{~m}$ (Jarvis et al. 2008). $\mathrm{Tu}$ and Liu (1990) found that the optimal grid resolution is $21 \mathrm{~km}^{2}$ for calculating the topographic relief in China. The optimal grid size for topographic analysis is $5 \mathrm{~km} \times 5 \mathrm{~km}$ for the Hengduan Mountains and Sichuan Basin (Liu et al. 2001). So, the original 90-m DEM was resampled to $5 \mathrm{~km}$ resolution to calculate independent variables in this paper.

\subsection{Methods}

\subsubsection{Conceptual model for precipitation pattern}

The conceptual model proposed by Lin and Wu (1990) indicates that there are three moving pathways of moisture-laden air masses into the plateau (Figure 2a), namely, the southeastern originating from the Bay of Bengal, the middle from the Indian Subcontinent and the western from the Indian Subcontinent and the Arabian Sea.

Moist air currents from the Bay of Bengal bring plentiful rainfall in the southeastern plateau along the lower Yarlung Zangbo River and in the south flank of Himalayas (Xu and Zheng 1996; Lin et al. 2013), and in the areas along the southeastern pathway (Huang and Shen 1984; Feng and Zhou 2012). Strong southwesterly and southerly airflows enter into the plateau, providing warm and humid air currents passing the valleys of the Himalayas (Qian and Shan 1984). The western pathway is closely related precipitation in the western Himalayas and the Karakoram Mountains (Zhang 1990; Zheng et al. 1997).

This paper used TMPA $3 \mathrm{~B}_{43} \mathrm{~V}_{7}$ monthly precipitation data to track trajectory variation of monthly precipitation (Figure $2 \mathrm{~b}$ ). Based on the precipitation trajectory analysis, we proposed an improved conceptual model for precipitation pattern, including moisture sources, transportation pathways and the area affected. This new model states that there exist mainly four moving routes of moisture-laden air masses into the plateau, namely, East (E), Southeast (SE), South (S) to West (W) as shown in Figure 2b. We summed up the amounts of monthly precipitation during the rainy season on each route and extracted locations of maximum precipitation in the periphery of the plateau as moisture sources.

\subsubsection{Topographical model for precipitation pattern}

Precipitation pattern in massive mountain areas is also closely related with the presence of topographical barriers to air mass transportation and the distance to moisture sources, which aggravate the loss of moisture (Broccoli and Manabe 1992; Lu et al. 2007). As for the Tibetan Plateau, its precipitation pattern can be quantitatively expressed as the function of watervapor flux in the four moisture sources mentioned above and the topographical conditions on the four moving routes. In this section, we developed a multivariate linear regression model with precipitation as the dependent variable and the topography-resulted attenuation of four-route moisture-laden air masses as independent variables.

\section{(1) Independent variables}

Generally, regions far away from moisture sources or obstructed by mountain barriers have less precipitation. Geographical orientation of mountain ranges often matters a lot for the 


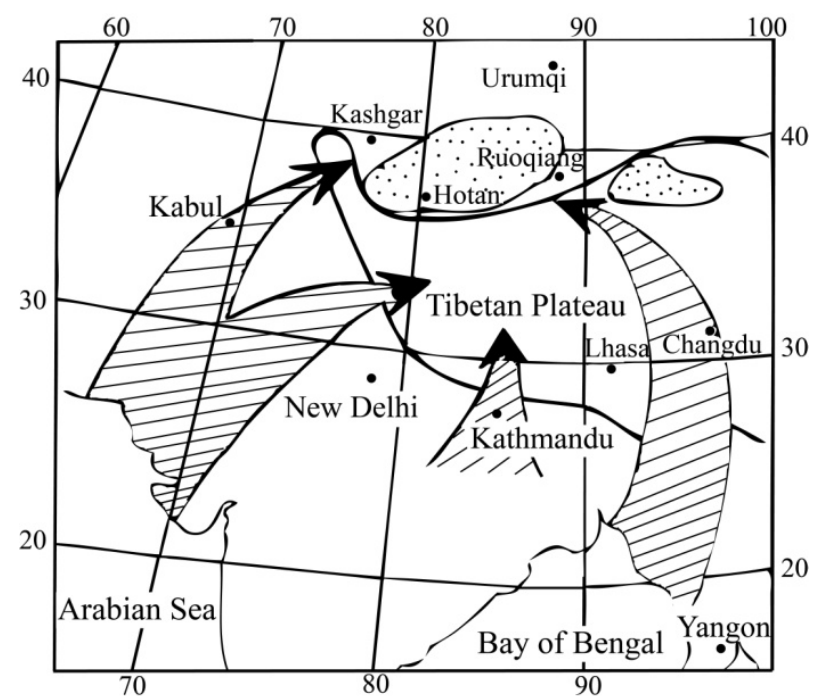

(a)

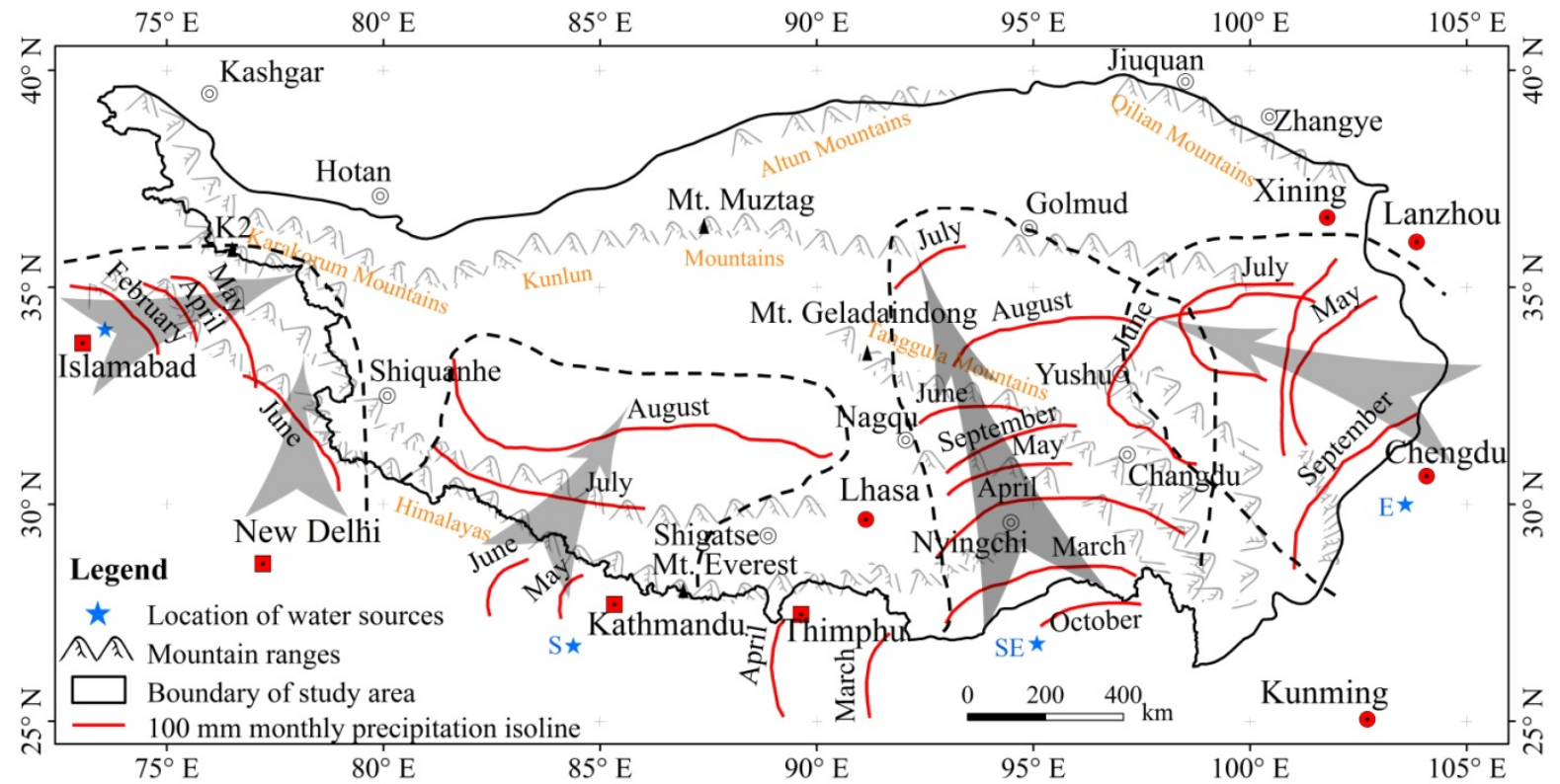

(b)

Figure 2 (a) The schematic of moisture-laden air masses transportation pathways (Lin and Wu 1990); (b) Trajectory map of $100 \mathrm{~mm}$ monthly precipitation identified with the monthly TMPA 3 B 43 V7 data.

transportation of moist air currents. If mountain ranges lie perpendicular to prevailing wind direction and moist air currents impinge on the windward flank of mountains, it will result in much more precipitation in the windward flank of mountain ranges but a rain shadow region in the leeward flank (Roe 2005).

To quantitatively describe topographic complexity along the routes between moisture source point and each grid in the plateau, we designed a topographic factor, Attenuation Variables (abbreviated as " $A V$ "). It has been shown that if mountain height is less than $500 \mathrm{~m}$ or the elevation of maximum precipitation, there is little difference in precipitation between windward and leeward flanks ( $\mathrm{Fu} \mathrm{1992),} \mathrm{and} \mathrm{that} \mathrm{the} \mathrm{maximum}$ precipitation occurs at the elevation of $2000 \mathrm{~m}$ in the southern flank of Himalayas (Alpert 1986; Liu 1992). According to these studies, we set two thresholds, $2000 \mathrm{~m}$ for $H^{\prime}$ and $500 \mathrm{~m}$ for $(\triangle H=$ $\left.H^{\prime}-H\right)$, so as to calculate attenuation variables.

The algorithm of Attenuation Variables is as follows:

First, we have extracted an elevation profile 
along the route from moisture sources to a given grid point (Tp) in the plateau (Figure 3). The search window with three values of elevation, $A=$ $\left[h_{1}, h_{2}, h_{3}\right]$, scans across the elevation profile along the moving route of moist air masses.

\section{Step (1): \\ $H=\operatorname{Min}(A)$.}

Step (2):

If $h_{2}=\operatorname{Max}(A)$,

$H^{\prime}$ is the elevation of $h_{2}$. When (1) $H^{\prime}>2000$ $\mathrm{m}$, or $\left(2 H^{\prime}<2000 \mathrm{~m}\right.$ and $\left(\Delta H=H^{\prime}-H\right)>500$ $\mathrm{m}$, the distance between moisture source and point $h_{2}(d)$ and the relative elevation $(\Delta H)$ will be written into a two-dimensional array $\mathrm{B}$. Then, the moving window moves forward to the next grid and the value of $H$ is reassigned.

If $h_{3}=\operatorname{Max}(A)$,

The moving window will move forward to the next grid and keep scanning.
Then, repeat the procedure above.

Step (3):

Finally, we sum up $(d \cdot \Delta H)$ of the array B using Equation (2). " $\Sigma(d \cdot \Delta H)$ " is the attenuation value of grid point $\mathrm{Tp}$ and can quantify the effect of topography on precipitation pattern in the plateau.

$$
A V=\sum(d \cdot \triangle H)
$$

Four attenuation variable surfaces for the four routes were calculated with SRTM DEM at a spatial resolution of $5 \mathrm{~km}$. Then, these variable surfaces were resampled based on the nearest neighbor method to $25 \mathrm{~km}$, the same size as TMPA precipitation data. As shown in Figure 4, four attenuation variable surfaces quantitatively reflect the effect of topography on the precipitation patterns. Attenuation variable rises with the increasing distance to the moisture sources and the complexity of topography.

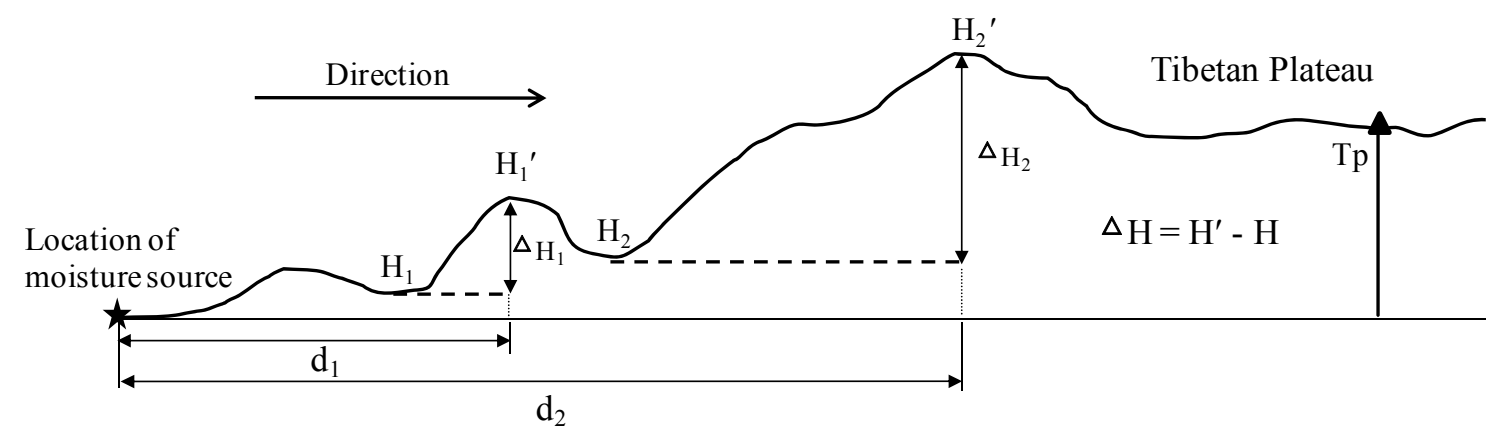

Figure 3 Elevation profile along the route from moisture source to any grid in the Tibetan Plateau. $d$ is the distance to moisture source, $H^{\prime}$ is the elevation of the top of topographic barriers, $H$ is the elevation of the previous valley of the topographic barrier, and $\left(\triangle H=H^{\prime}-H\right)$ is the relative elevation.

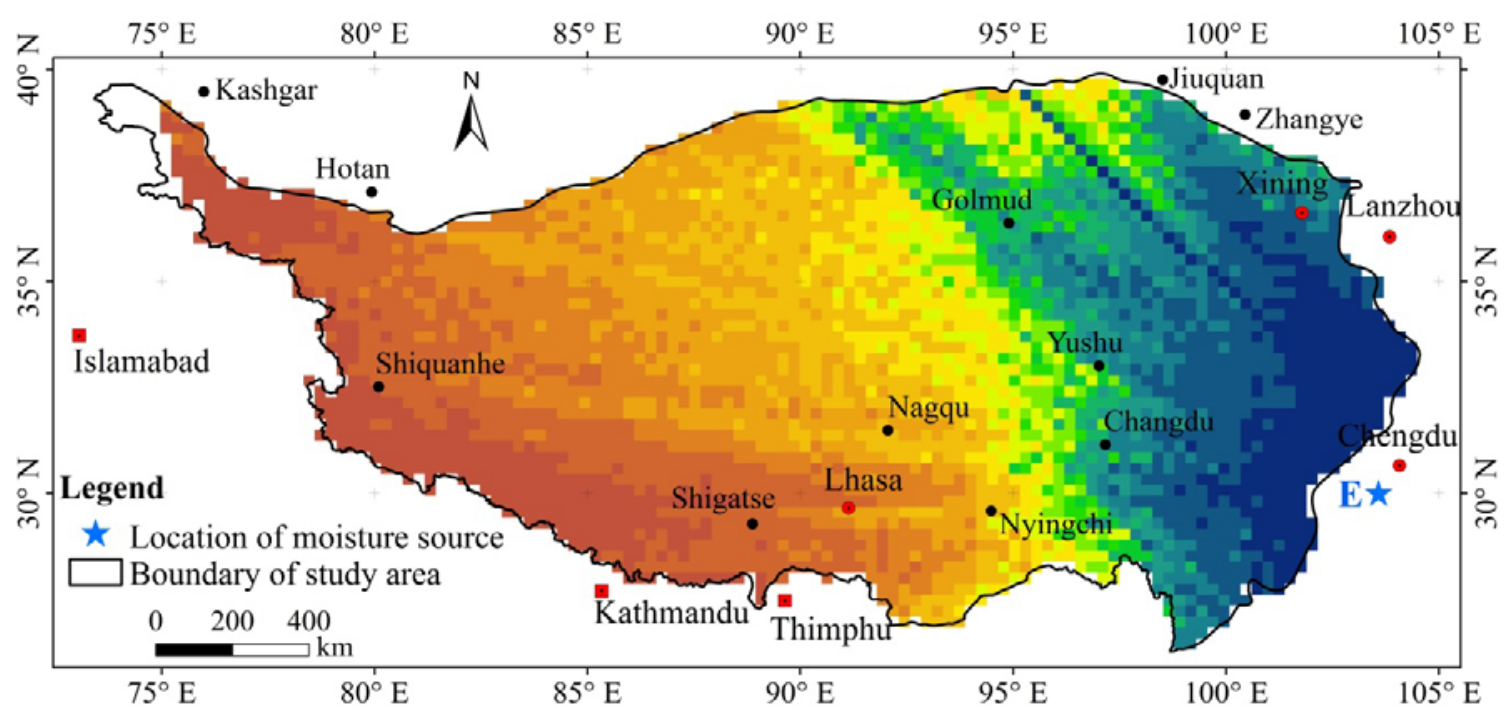

Figure 4 The spatial patterns of Attenuation Variables of four moisture sources (East, Southeast, South, West) in the Tibetan Plateau. (-To be continued-) 

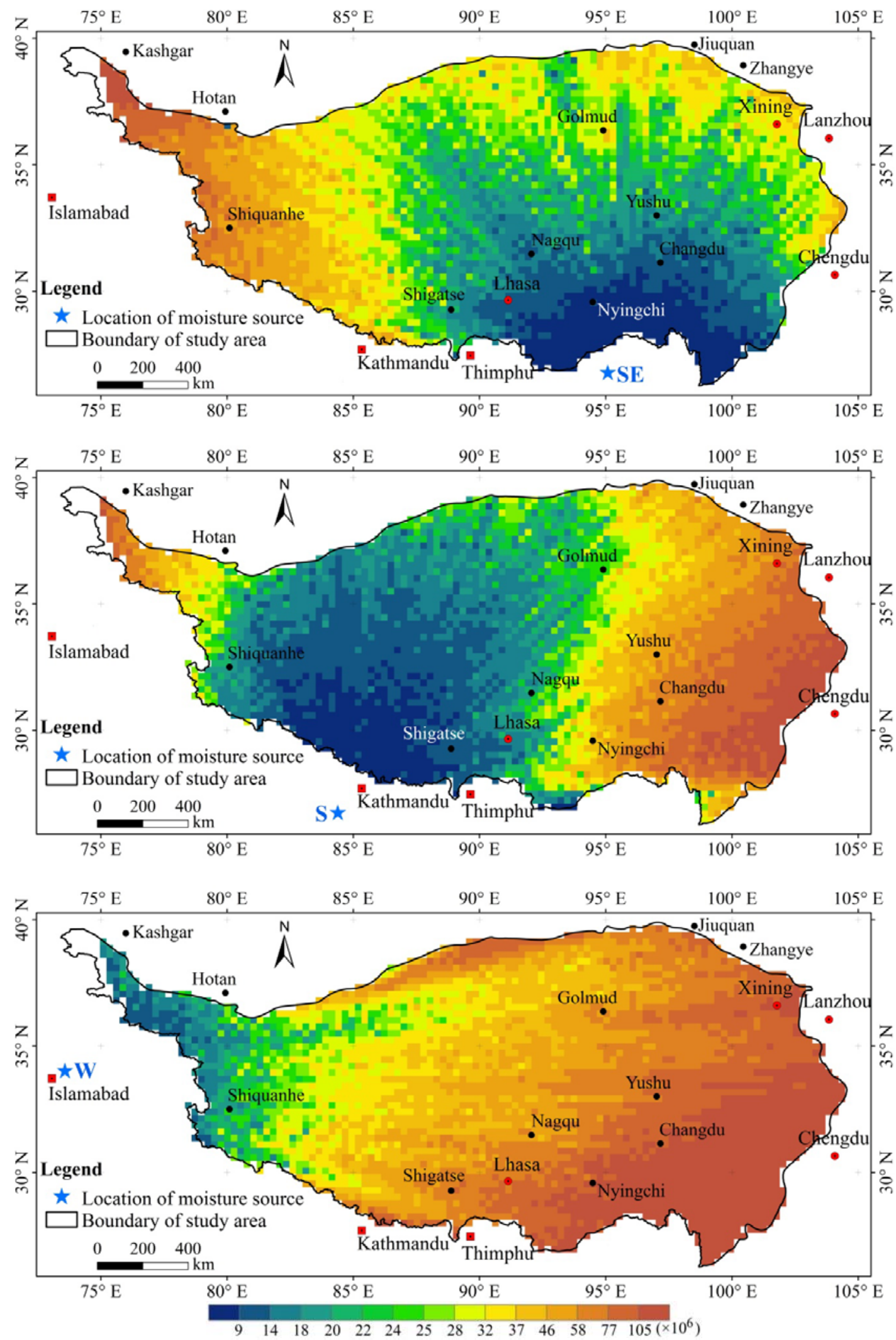

(-Continued-) Figure 4 The spatial patterns of Attenuation Variables of four moisture sources (East, Southeast, South, West) in the Tibetan Plateau. 


\section{(2) Modify variables by considering atmospheric water vapor fluxes}

The attenuation variables were normalized based on Equation (3).

$$
A V^{\prime}=Q(\text { MaxValue }-A V) / \text { MaxValue }
$$

where $A V^{\prime}$ is the normalization result, $A V$ gridspecific value of the attenuation variable surface, MaxValue the maximum value of attenuation variable surface, and $Q$ atmospheric water vapor flux $(Q)$ at moisture sources (East, Southeast, South, West) (Table 1). Then, we calculated normalized Attenuation Variables, $A V_{e}{ }^{\prime}$ for the east source, $A V_{s e}{ }^{\prime}$ for the southeast source, $A V_{s}{ }^{\prime}$ for the south source, and $A V_{w}{ }^{\prime}$ for the west source.

The four separate moisture sources have distinct capacities in shaping the precipitation pattern of the plateau. So, this paper used the NCEP/NCAR reanalysis data and Equation (1) to calculate the mean annual atmospheric water vapor flux $(Q)$ of moisture sources for four seasons (Table 1).

\section{(3) Develop multivariate linear regression model}

To quantify the effect of mass elevation to spatial precipitation patterns, we performed a multivariate linear regression method, with attenuation variables as the independent variables. The form of the model is as follows:

$\mathrm{P}=\mathrm{a}_{1} A V_{e}^{\prime}+\mathrm{a}_{2} A V_{s e}{ }^{\prime}+\mathrm{a}_{3} A V_{s}^{\prime}+\mathrm{a}_{4} A V_{w}{ }^{\prime}+\mathrm{a}_{5}$

where $\mathrm{P}$ is mean annual precipitation; $A V_{e}{ }^{\prime}$, $A V_{s e}{ }^{\prime}, A V_{s}{ }^{\prime}, A V_{w}{ }^{\prime}$ are attenuation variables for four moisture sources (East, Southeast, South, West), respectively; $a_{i}(i=[1 \sim 5])$ coefficients. The statistical analysis was performed using the proprietary software SPSS 17.0.

\section{Results}

\subsection{Collinearity Diagnostics of independent variables}

To carry out multiple regression analysis, correlation and multicollinearity of independent and dependent variables were diagnosed using software SPSS. It is shown that all four attenuation variables correlate significantly with mean annual precipitation pattern (Table 2). The attenuation variables have negative correlation with mean annual precipitation for the east and southeast routes, but strong positive correlation for the south and the west routes $(p<0.01)$.

We measured the degree of multicollinearity, according to the Tolerance value and Variance Inflation Factor (VIF) value (Kumari 2012) (Table 3). Generally, the closer the Tolerance value to Zero and if VIF exceeds 10, the greater the degree of multicollinearity. As shown in Table 2, the Tolerance value is greater than zero and the maximal VIF is 4.320 , less than 10 . The results indicate that the four variables are not perfect collinearity, which means that multiple regression analysis is feasible.

Table 1 The amount of atmospheric water vapor flux $(Q)$ of separate moisture sources for four seasons (Unit: $\left.\mathrm{kg} \cdot \mathrm{m}^{-1} \cdot \mathrm{s}^{-1}\right)$

\begin{tabular}{l|l|l|l|l|} 
& \multicolumn{4}{|c}{ Season } \\
\hline East & $60-70$ & 60 & 50 & 80 \\
\hline Southeast & 180 & 130 & 60 & 110 \\
\hline South & $90-100$ & 110 & $60-70$ & $40-50$ \\
West & $<30$ & $40-50$ & 30 & $20-30$
\end{tabular}

Table 2 Correlations between independent and dependent variables

\begin{tabular}{l|l|l|l|l|} 
& $A V^{\prime}$ & $A V_{s e^{\prime}}$ & $A V_{s}^{\prime}$ & $A V_{w^{\prime}}$ \\
\hline $\begin{array}{l}\text { Mean annual } \\
\text { Precipitation }\end{array}$ & $0.39^{* *}$ & $0.585^{* *}$ & $-0.546^{* *}$ & $-0.765^{* *}$ \\
\hline
\end{tabular}

Note: ** Correlation is significant at the 0.01 level.

Table 3 Results of Collinearity Diagnostics among independent variables.

\begin{tabular}{|l|l|l|}
\hline Variables & Tolerance & $\begin{array}{l}\text { Variance Inflation } \\
\text { Factor (VIF) }\end{array}$ \\
\hline Constant & - & - \\
\hline$A V_{e}{ }^{\prime}$ & 0.359 & 2.788 \\
\hline$A V_{s e^{\prime}}$ & 0.311 & 3.213 \\
\hline$A V_{s}{ }^{\prime}$ & 0.232 & 4.320 \\
$A V_{w}{ }^{\prime}$ & 0.232 & 4.317 \\
\hline
\end{tabular}

\subsection{Multivariate linear regression analysis}

A multivariate linear regression model was developed as follows, with precipitation as dependent variable and attenuation variable surfaces of four moisture sources as independent variables:

$$
\begin{aligned}
\mathrm{P}= & -10.68 A V_{e}{ }^{\prime}+6.844 A V_{s e}{ }^{\prime}-6.428 A V_{s}{ }^{\prime} \\
& -19.17 A V_{w}{ }^{\prime}+758.21
\end{aligned}
$$


Table 4 Summary of multivariate linear regression analysis (ANOVA, regression coefficients and their test of significance)

\begin{tabular}{|c|c|c|c|c|c|c|c|}
\hline $\begin{array}{l}\text { Coefficient of } \\
\text { determination }\left(R^{2}\right)\end{array}$ & $F$ & Variables & $\begin{array}{l}\text { Unstandardized } \\
\text { coefficients }\end{array}$ & $\begin{array}{l}\text { Standardized } \\
\text { coefficients }\end{array}$ & $\begin{array}{l}\text { Contribution } \\
\text { rate }(\%)\end{array}$ & $t$ & Sig. \\
\hline \multirow{5}{*}{0.70} & \multirow{5}{*}{$\begin{array}{l}2178.454 \\
(p=0.000)\end{array}$} & Constant & 758.21 & & & 25.846 & 0.000 \\
\hline & & $A V_{e}^{\prime}$ & -10.68 & -0.432 & 23.59 & -28.853 & 0.000 \\
\hline & & $A V_{\text {se }}^{\prime}$ & 6.844 & 0.596 & 32.56 & 37.104 & 0.000 \\
\hline & & $A V_{s}^{\prime}$ & -6.428 & -0.43 & 23.48 & -23.068 & 0.000 \\
\hline & & $A V_{w}^{\prime}$ & -19.17 & -0.373 & 20.37 & -20.035 & 0.000 \\
\hline
\end{tabular}

The model has a high coefficient of determination $\left(R^{2}=0.70\right)$ and low $F$-value of analysis of variance (ANOVA) (Table 4), which indicates that the multivariate linear regression equation could be adequately used to explain precipitation pattern. The $T$-test of regression coefficients demonstrates that the four independent variables have significant correlations with mean annual precipitation.

Contribution rates of the four independent variables can be calculated from their respective Standardized Coefficients. The southeast source contributes the most $(32.56 \%)$ to the spatial pattern of mean annual precipitation of the plateau; the east and south sources roughly the same (23.59\% and $23.48 \%$, respectively), and the west source the least (20.37\%).

\subsection{Residual analysis}

To analyze the performance of the model developed, we calculated the residual between the predicted and actual values of precipitation. According to the results of residual analysis (Figure 5), most points were distributed along the diagonal

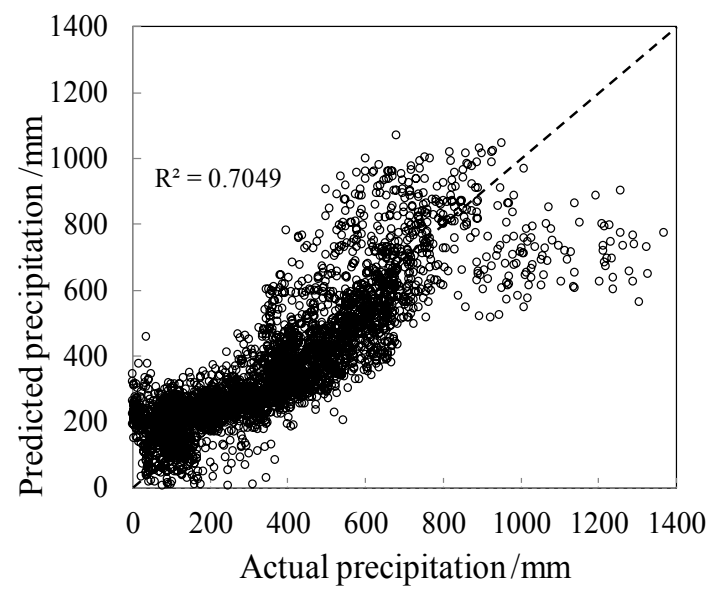

Figure 5 Scatter plot of model predicted precipitation and actual value (The dashed line is the best-fitting line). line, which indicates that the model functions well in most places of the plateau. A few large deviations are distributed in the right side of the plot with high actual precipitation. These deviations are located near the four moisture sources, which are dominantly controlled by single water source variable. Despite these outliers, this model is rather robust in explaining precipitation pattern of the plateau.

\section{Discussion}

This study has developed a topographic model to quantitatively reveal the topographic effect on precipitation pattern in the Tibetan Plateau. Firstly, we improved the conceptual model for precipitation pattern in the plateau by identifying four moisture sources (east, southeast, south, and west). The moving routes of moisture-laden air masses and landform relief along the routes were used to explain the spatial patterns of precipitation in the plateau. Based on the new conceptual model, this paper combined the distance to moisture sources (east, southeast, south, west directions) with mountain relative elevation to quantify the effect of topography to precipitation by defining four "Attenuation Variables". Then, we normalized the attenuation variables and further modified them based on atmospheric water vapor flux. Finally, we quantitatively developed a multivariate linear regression equation to explain precipitation pattern with the four attenuation variables. Our model can explain about $70 \%$ of the spatial variation of mean annual precipitation in the Tibetan Plateau.

In this paper, we simplified moisture trajectories in the plateau to a linear way rather than considering them in more specific or complex routes. Moreover, this model assumes that precipitation at any point of the plateau resulted 
from all the four moisture sources. In reality, any of the four moisture sources is unlikely to bring rainfall to the whole plateau, but only in parts of the plateau and in different seasons, e.g., the eastern pathway begins to work in May and ends in September; the southeastern begins in March and ends in October; the southern works in July and August; and the western has season variation in summer and winter. These and other simplifications may introduce bias into the model and should be considered in the future studies.

\section{Conclusion}

Moisture sources and topography on the moving routes of moisture-laden air masses all play a significant role in determining the spatial precipitation pattern of the Tibetan Plateau. According to our study, moist air currents from the southeast direction (i.e., the Bay of Bengal) contribute the most to the precipitation pattern of

\section{References}

Alpert P (1986) Mesoscale indexing of the distribution of orographic precipitation over high mountains. Journal of Climate and Applied Meteorology 25(4): 532-545. DOI: 10.1175/1520-0450(1986)025

Anders AM, Roe GH, Hallet B, et al. (2006) Spatial patterns of precipitation and topography in the Himalaya. Special Papers-Geological Society of America 398: 39-53. DOI: 10.1130/2006.2398(03)

Basist A, Bell GD, Meentemeyer V (1994) Statistical relationships between topography and precipitation patterns. Journal of Climate 7(9): 1305-1315. DOI: 10.1175/15200442(1994)007<1305:SRBTAP>2.0.CO;2

Broccoli AJ and Manabe S (1992) The effects of orography on mid-latitude northern-hemisphere dry climates. Journal of Climate 5(11): 1181-1201. DOI: 10.1175/1520-0442(1992)005< 1181:TEOOOM>2.0.CO;2

Feng L and Zhou T (2012) Water vapor transport for summer precipitation over the Tibetan Plateau: Multi-dataset analysis. Journal of Geophysical Research: Atmospheres 117(D2O): 85-99. DOI: 10.1029/2011JD017012

Fielding E, Isacks B, Barazangi M, et al. (1994) How flat is Tibet. Geology 22(2): 163-167. DOI: 10.1130/0091-7613(1994)022< 0163:hfit>2.3.co;2

$\mathrm{Fu}$ BP (1992) The effect of topography and elevation on precipitation. Acta Geographica Sinica 47(4): 302-314. (In Chinese)

Gao DY, Zou H and Wang W (1985) Influence of water vapor pass along the Yarlung Zangbo River on precipitation. Mountain Research 3(4): 239-249. (In Chinese)

Gao YC and Liu MF (2013) Evaluation of high-resolution satellite precipitation products using rain gauge observations over the Tibetan Plateau. Hydrology and Earth System Sciences 17(2): 837-849. the plateau. This is consistent with the point of view of the so-called "wet tongue" existing in the "Great Bend" of the lower Yarlung Zangbo (Lin and Zheng 1991). The significance of the western moisture source is clearly recognized for the precipitation pattern of the plateau.

The findings of this work can improve our understanding of the mechanism of precipitation pattern in the Tibetan Plateau, which may contribute to the future improvement of mountain climate models. This paper could also help understand the effect of moisture reduction by mountain masses and promote in-depth study of mass elevation effect (Yao and Zhang 2015; Zhao et al. 2015).

\section{Acknowledgements}

This study was funded by the National Natural Science Foundation of China (Grant Nos. 41421001 and 41030528).
Hao ZC, Tong K, Zhang LL, et al. (2011) Applicability analysis of TRMM precipitation estimates in the Tibetan Plateau. Journal of China Hydrology 31(5): 18-23. (In Chinese)

Huang FJ and Shen RJ (1984) Analysis on water vapor sources and budget of the Tibetan Plateau in the summer monsoon. In: Meteorology science symposium of Tibetan Plateau (1). Science Press, Beijing, China. pp 215-224. (In Chinese)

Huffman GJ, Bolvin DT, Nelkin EJ, et al. (2007) The TRMM Multi-satellite Precipitation Analysis (TMPA): Quasi-global, multiyear, combined-sensor precipitation estimates at fine scales. Journal of Hydrometeorology 8(1): 38-55. DOI: 10.1175/jhm560.1

Jarvis A., Reuter HI, Nelson A, et al. (2008) Hole-filled SRTM for the Globe Version 4, available from the CGIAR-CSI SRTM 9om Database (http://srtm.csi.cgiar.org).

Ji X and Chen YF (2012) Characterizing spatial patterns of precipitation based on corrected TRMM $3 \mathrm{~B} 43$ data over the mid Tianshan Mountains of China. Journal of Mountain Science 9(5): 628-645. DOI: 10.1007/s11629-012-2283-Z

Jia SF, Zhu WB, Lu AF, et al. (2011) A statistical spatial downscaling algorithm of TRMM precipitation based on NDVI and DEM in the Qaidam Basin of China. Remote Sensing of Environment 115(12): 3069-3079. DOI: 10.1016/ j.rse.2011.06.009

Kalnay E, Kanamitsu M, Kistler R, et al. (1996) The NCEP/NCAR 40-year reanalysis project. Bulletin of the American Meteorological Society 77(3): 437-471.

Kumari SS (2012) Multicollinearity: Estimation and elimination. Journal of Contemporary Research in Management 3(1): 87-95.

Kummerow C, Barnes W, Kozu T, et al. (1998) The Tropical Rainfall Measuring Mission (TRMM) sensor package. Journal of Atmospheric and Oceanic Technology 15(3): 809-817. DOI: 
10.1175/1520-0426(1998)015<0809:ttrmmt>2.0.co;2

Liao K (1990) The Atlas of the Tibetan Plateau. Science Press, Beijing, China. p 66. (In Chinese)

Lin ZY and Wu XD (1990) A preliminary analysis about the tracks of moisture transportation in the Qinghai-Xizang Plateau. Geographical Research 9(3): 33-40. (In Chinese)

Lin ZY and Zheng D (1991) Moisture transportation pathways to the Qinghai-Tibetan Plateau and their geoecological significance. Chinese Journal of Arid Land Research 4(1): 4147.

Lin ZY, Zhang XQ and Yin ZY (200o) Climate: past, present, and future. In: Zheng D, et al. (eds.), Mountain Geoecology and Sustainable Development of the Tibetan Plateau. Kluwer Academic Pub 57, Springer, Netherlands. pp 89-112.

Lin ZQ, Wen SJ and Zhou ZB (2013) The objective clustering of tropical storms tracks over the Bay of Bengal. Journal of Tropical Meteorology 29(6): 973-983. (In Chinese)

Liu GW (1992) Hydro-meteorological characteristics of the Tibetan Plateau. Journal of Hydraulic Engineering (5): 1-8. (In Chinese)

Liu XD and Yin ZY (2002) Sensitivity of East Asian monsoon climate to the uplift of the Tibetan Plateau. Palaeogeography, Palaeoclimatology, Palaeoecology 183(3-4): 223-245.

Liu XH, Yang QK, and Tang GA (2001) Extraction and application of relief of China based on DEM and GIS methods. Bulletin of Soil and Water Conservation 21(1): 5759. (In Chinese)

Lu CX, Wang L, Xie GD, et al. (2007) Altitude effect of precipitation and spatial distribution of Qinghai-Tibetan Plateau. Mountain Research 25(6): 655-663. (In Chinese)

Owen LA, Finkel RC, Barnard PL, et al. (2005) Climatic and topographic controls on the style and timing of late Quaternary glaciation throughout Tibet and the Himalaya defined by 10 Be cosmogenic radionuclide surface exposure dating. Quaternary Science Reviews 24(12): 1391-1411. DOI: 10.1016/j.quascirev.2004.10.014

Peixoto JP and Oort AH (1983) The atmospheric branch of the hydrological cycle and climate. In: Street $\mathrm{P}$ et al. (eds.), Variations in the global water budget. Springer, Netherlands. pp 5-65.

Qi WW, Zhang BP, Pang Y, et al. (2013) TRMM-data-based spatial and seasonal patterns of precipitation in the QinghaiTibet Plateau. Scientia Geographica Sinica 33(8): 999-1005. (In Chinese)

Qian ZA and Shan FM (1984) Analysis on primary vortex in rainy season in the west of the Tibetan Plateau. In:
Meteorology science symposium of Tibetan Plateau (1). Science Press, Beijing, China. pp 229-242. (In Chinese)

Roe GH (2005) Orographic precipitation. Annual Review of Earth and Planetary Sciences 33: 645-671. DOI: 10.1146/ annurev.earth.33.092203.122541

Tu HM and Liu ZD (1990) Demonstrating on optimum statistic unit of relief amplitude in China. Journal of Hubei University (Natural Science) 12(3): 266-271. (In Chinese)

$\mathrm{Xu} \mathrm{JM}$ and Zheng XJ (1996) Upper tropospheric moisture distribution over the Tibetan Plateau as revealed from GMS- 5 water vapor images. Quarterly Journal of Applied Meteorology 7(2): 246-251. (In Chinese)

Yang YC, Gao DY and Li BS (1987) A preliminary analysis on the tracks of moisture transportation in the lower reaches of the Yarlung Zangbo River. Science in China (series D) (8): 893902. (In Chinese)

Yao YH and Zhang BP (2015) The mass elevation effect of the Tibetan Plateau and its implications for alpine treelines. International Journal of Climatology 35(8): 1833-1846. DOI: 10.1002/joc.4123

Ye DZ and Wu GX (1998) The role of the heat source of the Tibetan Plateau in the general circulation. Meteorology and Atmospheric Physics 67(1-4): 181-198.

You QL, Fraedrich K, Ren GY, et al. (2012) Inconsistencies of precipitation in the eastern and central Tibetan Plateau between surface adjusted data and reanalysis. Theoretical and Applied Climatology 109(3-4): 485-496.

Zeng H, Li L and Li J (2012) The evaluation of TRMM Multisatellite Precipitation Analysis (TMPA) in drought monitoring in the Lancang River Basin. Journal of Geographical Sciences 22(2): 273-282. DOI: 10.1007/s11442-012-0926-1

Zhao F, Zhang BP, Zhang S, et al. (2015) Contribution of mass elevation effect to the altitudinal distribution of global treelines. Journal of Mountain Science 12(2): 289-297. DOI: 10.1007/s11629-014-3223-x

Zhang BP (1990) Physical features and vertical zones of the Karakoram and Ngari-Karakoram Mountains. Journal of Arid Land Resources and Environment 4(2): 49-63. (In Chinese)

Zhang BP (2000) Kunlun Mountains Region. In: Zheng D, et al. (eds.), Mountain Geoecology and Sustainable Development of the Tibetan Plateau. Kluwer Academic Pub 57, Springer, Netherlands. pp 349-372.

Zheng XJ, Xu JM and Li XZ (1997) Characteristics of water vapor transfer in upper troposphere over Qinghai-Xizang Plateau in summer. Plateau Meteorology 16(3): 274-281. (In Chinese) 